\title{
Las Contribuciones Especiales y los demás medios que otorga la Ley del Suelo para la ejecución de los Planes y Proyectos urbanisticos
}

\author{
por \\ NEMESIO RODRIGUEZ MORO \\ Doctor en Derecho. Diplomado en Administración Local
}

SUMARIO: 1. Las Contribuciones Especiales.-2. Directrices de la Ley del Suelo.-3. Sistemas de ejecució́li de los Planes uRbanístioos en la Ley deE SuElo: A) Sistema de Cooperación: a), Obligaciones de los propietarios en este sistema. b) Procedimiento. B) Sistema de Expropiación: a) Notas de este sistema. b) Quién puede llevarlo a cabo. c) Procedimiento. d) Limitaciones que impone a los propietarios afectados. e) Obligaciones que impone al expro. piar.te. C) Sistema de Compensación: a) Idea de este sistema. b) Proyectos urbanisticos para realiza: por Compensación. c) Iniciativa en el sistema de Compensación. d) Incumplimiento de las obligaciones contraidas por los propietarios. e) Otias facultades de la Junta de Compersación. D) Sistema de Cesion de terrenos viales.

\section{Las Contribuciones Especiales}

No es preciso poner de relieve la importancia que para los Ayuntamientos tiene el que los medios jurídicos y económicos de que 'es dota la Ley para llevar a cabo y poner en ejecución los Planes y Proyectos de urbanización, sean no solo teóricamente perfectos, sino de fácil aplicación. A veces sucede que las normas jurídicas, con el deseo de llegar a la perfección técnica, originan tales confusiones y dificultades de tanta monta, que resuitan prácticamente inoperantes.

Sin llegar a la afirmación de que esto haya ocurrido de una 
manera totai y absoiuta con las Contribuciones Especiales, no es menos cierto, sin embargo, que aun cuando, desde el punto de vista técnico, las Contribuciones Especiales han tenido en nuestro Derecho positivo una elaboración muy acabada, no han rendido en el orden práctico el fruto que cabía esperar de un tan bien tratado ouerpo legal, como el establecido ai efecto.

El expediente de imposición de las Contribuciones Especiales es dificultoso en cuanto a múltiples de sus actuaciones, por ejemplo, fijar las superficies afectadas, los aumentos de valor, etc., y ofrece abundantes recovecos, desde donde puede fácilmente atacársele para dejar sin efecto la imposición o disminuir la cuota en tal porcentaje, que resulte ridícula en proporción al elevado costo de la obra. Y entonces, la bien concebida idea de repartir equitativamente las cargas públicas de acuerdo con los beneficios que las obras producen, trayendo a tributar de una manera especial a cuantos de un modo especial se beneficien, bien con el aumento efectivo del valor de sus fincas, bien con los beneficios de otro orden que pudieran derivarse para los mismos, queda sin efectividad práctica.

Basta echar una mirada sobre la jurisprudencia del Tribunal Supremo desde 1924 a la fecha, para apreciar que, en un porcentaje muy elevado, cada vez que se promovió un recurso sobre la aplicación de las Contribuciones Especiales, el fallo ha sido desfavorable para la Corporación municipal. Y no digamos nada del gran número de expedientes que han quedado segados en flor, y sin efectiva aplicación de las Contribuciones Especiales, por haberse dejado incumplido alguno de sus muchos trámites, y que los propios funcionarios de la Corporación han considerado mejor no seguir adelante en la exacción y sufragar con los fondos de la Caja General obras que debieran haberse satisfecho por los especialmente beneficiados.

Es verdad que la imposición de las Contribuciones Especiales se ha venido abriendo camino de una manera trabajosa y que hoy, con el celo desplegado por competentes y celosos funcionarios y la experiencia obtenida, son muchos los Ayuntamientos que pueden llevar a buen fin un expediente de imposición de 
Contribuciones Especiales. Pero también es cierto que muy a menuido la Contribución Especial no es de la importancia que debia ser, y que en aras de facilitar el camino de ia imposicion, constantemente los Ayuntamientos tienen que ir cediendo de sus derechos y con ello hacer cargar a la Caja colectiva con gastos y dispendios que razonablemente debían soportar los especialmente beneficiados por consecuencia de las obras a realizar.

\section{Direćtrices de la Ley del Suelo}

Superando estas dificultades, la nueva Ley de Régimen del Suelo y Ordenación Urbana de 12 de mayo de 1956 ofrece otros medios jurídicos para poder facilitar la realización de los Planes y Proyectos urbanísticos a cargo de quienes efectivamente obtienen beneficios inmediatos y directos como consecuencia de tal actividad urbanística. Y correlativamente a estos medios jurídicos of rece compensaciones económicas a los propietarios que han de soportar estas cargas y a los Ayuntamientos que llevan a cabo la trascendental labor que es ei contenido de ia Ley del Régimen del Suelo, la cual no sólo ordena la urbanización propiamente dicha, es decir, abrir calles y plazas, instalar jardines y parques y proveer a los servicios fundamentales de agua, electricidad, gas, saneamiento, etc., sino que procura la construcción de los solares resultantes en las mejores condiciones, a fin de resolver el acuciante problema de la vivienda.

La Ley del Suelo, como se indicaba anteriormente, ha superado el insuficiente medio jurídico de las Contribuciones Especiales para facilitar la realización y puesta en ejecución de los Planes y Proyectos de urbanización y construcción de los solares resultantes. Sin desechar totalmente este procedimiento de las Contribuciones Especiales, éstas van a quedar relegadas a un segundo término, puesto que los Proyectos de urbanización se podrán llevar a ejecución mediante otros sistemas o regímenes que ofrecen una mayor libertad de movimientos para la efectiva ejecución de los Planes y para el justo reparto de las cargas y beneficios que de ellos se deriven. 
Una directriz interesante es la de atraer la iniciativa particular para cooperar a ca realización de los Planes de urbanización. Cuando esa iniciativa faitase, entonces la Adminisíración podrá utilizar medios de relativa holgura jurídica y económica en orden a la puesta en marcha de la actividad urbanística.

Las tendencias conforme a las cuales se ordenan en la Ley del Suelo ios sistemas de ejecución de los Planes y Proyectos urbanísticos, pueden concretarse en estas tres:

a) Atracción de la iniciativa privada.-Procura que los Planes urbanísticos se lleven a ejecución por los particulares bajo la supervisión, fiscalización y control de la Corporación muni cipal correspondiente. Para ello otorga no sólo facilidades de orden jurídico, sino beneficios importantes de orden fiscal y cesión de participaciones de Impuestos del Estado o Arbitrios municipales a los que colaboran de ese modo en la $r$ alización de los Planes urbanísticos.

b) Faciiidad de aplicar la expropiación forzosa.-Como luego se verá, la Administración municipal y, en generai, los órganos que realizan la actividad urbanística, adquiere una gran libertad de movimientos para realizar los Proyectos de urbanización mediante la expropiación forzosa y pago justo del valor de los terrenos que se expropian.

c) Concreción de las obligaciones de los propietarios afectados por la urbanización.-Tanto en el sistema de cooperación como en el de compensación, se fijan en detalle y con minuciosidad cuáles son las obligaciones de los propietarios, lo cual representa un notorio avance sobre las Contribuciones Especiales. A la vez se establece una compensación a los propietarios cooperadores, según ya se ha indicado anteriormente.,

3. Sistemas de ejecución de los Planes urbanísticos en la LEY DEL SUELo

Los sistemas o regímenes consagrados por la nueva Ley del Suelo son cuatro, a los que denomina:

a) De Cooperación.

b) De Expropiación. 
c) De Compensación.

“d) De Cesión de viales.

Veamos las características que presenta cada uno de estos sistemas o regímenes de ejecución de los Planes y Proyectos urbanísticos.

\section{A). Sistema de Cooperación..}

Cuando en el preámbuio de la Ley del Suelo se hace referencia al sistema de Cooperación, se escribe: "sobre el supuesto de que la iniciativa individual, debidamente estimulada y dirigida, es insustituíbie, ha de tender el régimen de Cooperación a estimular la urbanización y edificación por los propietarios». Y, así, considera claramente aplicable este sistema a zonas que en lai ciudad ofrezcan un porvenir inmediato, achacando la lentitud de la movilización económica para la expansión de las poblaciones a la excesiva centralización de las obras por los Ayunta mientos, siendo así que estima el legislador como orientacion mejor y más certera atraer el mayor número posible de colaboraciones individuales, sin perjuicio de las funciones de dirección y fiscalización que a la Administración están reservadas.

Tal vez estas palabras del preámbulo de la Ley fueran más apropiadas para el sistema de Compensación que para el de Cooperación, porque es en el sistema de Compensación donde la iniciativa privada se pone más de relieve y donde la facultad de realización completa, desde la elaboración del Proyecto de ejecución dentro del Plan hasta su material realización, está totalmente en manos de los particulares, cosa que no se da con tanta fuerza en el sistema de Cooperación.

a) .. Obligaciones de los propietarios en este sistema. .

- Consigna la Ley del Suelo las obligaciones de los propietarios de terrenos comprendidos en el sector, polígono o manzana que se refieren las obras de urbanización que se trata de llevar a cabo, estableciendo al efecto para dichos propietarios las siguientes obligaciones: 
$\left.a^{\prime}\right)$ La cesión gratuita de la superficie que haya de ocupar la calle o plaza de ancho normal, es decir, lo que se llama el terreno o superficie vial.

b') La cesión gratuita de la superficie destinada a parques y a jardines públicos.

c') La contribución al costo de las obras de plazas y calles proyectadas en proporción al valor de los solares resultantes de la parcelación.

d') La edificación de los solares en los plazos que se fijen.

En casos de calles, plazas, jardines y parques de ancho superior al normal se establecen limitaciones a la obligación de ceder terrenos y de contribuir al costo de las obras. "

Puntualizando estas obligaciones de los propietarios afectados por las obras, el legislador, en los artíoulos 116 y siguientes, fija los términos de aquéllas, según lo que a seguido se consigna :

\section{a') Cesion de superficies viales.}

La cesión gratuita alcanzará para cada propietario y en cada manzana a la mitad de la anchura de la vía pública en todo el frente de la alineación del terreno de que se trata a la calle en cuestión. Es decir, que en este caso, si suponemos que todas y cada una de las fincas fronteras a la vía púbica llegan exactamente a la mitad de la calle, es decir, al eje de la misma, nos encontra. ríamos con que cada propietario cedería con carácter gratuito la mitad de la anchura de la calle. Pero como esto no es normal que ocurra, sino que por la irregularidad de los solares o por el modo diverso como les afecta el trazado de la calle, unos tendrían que ceder mayor cantidad que la que les correspondería, y otros en cambio menos, con $\downarrow$ lo cual se produciría una manifiesta desigualdad en las cargas fiscales, he aquí que entonces se podría pedir la reparcelación de los terrenos para que cada propietario ceda exactamente lo que le çorresponde, según el anterior precepto. 
Aunque nada dice la Ley, tal vez pudiera acudirse ai procedimiento de formar una masa común, una especie de caja compensatoria, a la que cada propietario aportase la parte de su terreno que pasa a ser vial, y valorando ei terreno que se aporta y el que se debiera aportar gratuitamente por cada propietario, compensar al que se le hubiera ocupado una porción de terreno mayor de la que debiera aportar según Ley.

Cuando la calle o plaza tenga mayor anchura de 12 metros no podrá exigirse como cesión más de la que resulte de aplicar al frente de alineación una profundidad equivalente a los dos tercios de la altura máxima edificab'e sobre el solar.

En el caso de que la parcela estuviese emplazada en un cruce de calles, la obligación de cesión gratuita abarcará también la parte del cruce comprendido entre las proiongaciones de los ejes de las calles con idéntica limitación; es decir, que en ningún caso podría sobrepasar una profundidad equivalente a los dos tercios de la altura máxima edificable sobre el solar.

\section{b') Cesión a terrenos destinados a parques y jardines pú blicos.}

La. cesión gratuita de los terrenos que hayan de ser ocupados por los parques y jardines públicos será igual a la décima parte de la superficie edificable del sector para cuyos servicios se establezcan, en el caso de que la altura de la edificación no exceda de cinco plantas, pudiéndose incrementar hasta un 15 por 100 para las fincas que den vista sobre el parque o jardín, y hasta un 12 por 100 para las radicadas a 300 metros del perímetro exterior del parque o jardín correspondiente. En el caso de que exceda de cinco plantas la posibilidad de edificación, la aportación obligatoria para los propietarios será mayor según la proporción correspondiente a la mayor edificación permitida.

\section{c') Contribución al costo de las obras a realizar.}

En este renglón los propietarios comprendidos en el polígono o manzana correspondiente vienen ob'igados a costear el importe de las obras siguientes: 
Explanación, encintado y pavimentación de las aceras y de la calzada, alcantarillado, drenaje si fuera preciso, alumbrado público y las redes correspondientes para el suministro de agua, electricidad y gas si lo hubiere, plantaciones de arboiado y de jardinería y elementos decorativos que estén previstos y precisados en el Plan de urbanización, dejando a salvo el que por convenios establecidos con organismos, compañías o empresarios concesionarios de servicios públicos, se hubiera dispuesto otra cosa.

E' legislador prevé en el artículo $\mathbf{1 1 7}$ de la Ley que los propie tarios tendrán derecho a reintegrarse de ios gasios de instalación de las redes de suministro de agua, electricidad y gas, de las empresas que prestaran los servicios, salvo la parte en que deban contribuir los usuarios según los Reglamentos de cada uno de los servicios indicados.

En el caso de que la anchura de las vías y plazas que hubieran de urbanizarse excediese de 12 metros, los propietarios no vienen obiigados a abonar el costo íntegro, sino sólo aquel que resulte de la proporción señalada con anterioridad respecto de la cesión de terrenos viales, cargando el Ayuntamiento con el exceso como representante de la colectividad.

Las obligaciones antes indicadas se dan igualmente cuando se trate de terrenos destinados a edificios o a servicios públicos, pues en tal caso vendrían igualmente obligadas las Entidades públicas titulares de dichos terrenos o edificios o servicios a sufragar el importe de lo que le corresponda, como un: propietario más, según así lo establece el artículo 117 de la Ley.

Bien se echa de ver, por lo antes dicho, que las obligaciones de los propietarios en este sistema de Cooperación son mayores que las que imponía el régimen de Contribuciones Especiales en la Ley de Régimen local, y que con este sistema se iluminan muchos de los problemas de las Contribuciones Especiales, aun cuando también los ofrece en su aplicación, sobre todo hasta que la experiencia y normas complementarias permitan ir despejando algunas cuestiones que dan lugar a dudas y confusión. 
d') Edifucación de los solares en hos plazos establecidos.

Esta obligación resulta congruente con la finalidad social que persigue la Ley. Los plazos para cumplir tal obligación se señalarán en el Plan o Proyecto de ejecución de las obras, y a tal plazo habrán de atenerse los propietarios con estricto rigor, pues de otro modo y si no se cumpliesen, podrán ser expropiados, como así lo establece el artículo 119.

b) Procedimiento.

La iniciativa para la ejecución de un proyecto determinado partirá de la Corporación municipal, que deberá adoptar acuerdo declarando de interés inmediato la urbanización de un polígono o manzana determinados y la edificación consecutiva de los solares resultantes, aplicando el sistema de Cooperación.

Una vez adoptado este acuerdo por el Ayuntamiento en Pleno, se convocará a los propietarios, a los que se informará ampliamente de las características de las obras a realizar y del régimen de Cooperación que se aplica para la ejecución de las mismas, requiriéndolos para que en el plazo de dos meses manifiesten si están conformes con la propuesta y se comprometen a cumplir las obligaciones de ceder gratuitamente las superficies viales y de parques y jardines; contribuir a las obras en la proporción que se determina en el proyecto y a construir los solares resultantes en los plazos que en el acuerdo se fija.

Los propietarios, que pueden constituir una Asociación administrativa de la manzana o el sector de que se trate, habrán de contestar dentro del indicado plazo. Si no lo hicieren, o si la aceptación fuera inferior al 60 por 100 de la superficie o del valor de los terrenos, el Ayuntamiento podrá seguir adelante en la ejecución del proyecto, expropiando el polígono, sector o manzana de referencia, procediendo a su urbanización y enajenando después los solares resultantes. 
Los Ayuntamientos exciuirán de la expropiación a los propietarios que hubieren aceptado el régimen de Cooperación, los cuales quedarán obligados, en consecuencia, al compromiso contraído a: dar su conformidad de sistema o régimen de Cooperación.

La Ley aclara en su artículo 120 que las disposiciones del sistema de Cooperación lo mismo se aplicarán a los propietarios individuales o asociados que a las empresas que se dediquen a la urbanización y edificación, y que, en todo caso, podrán los titulares de las propiedades afectadas cumplir sus obligaciones a este respecto a través de empresas urbanizadoras que sufraguen las obras o que las illeven a cabo por sí mismas mediante las compensaciones que convengan con aquellos propietarios, y que podrán consistir en la cesión de terrenos o del todo o parte de los beneficios económicos que les correspondan. Y, aunque no lo diga la Ley, podrán utilizarse otras variadas combinaciones que empresas urbanizadoras y propietarios acuerden, puesto que, en definitiva, de lo que aquí se trata es de estimular la urbanización y la edificación subsiguiente de los terrenos.

\section{B) Sistema de Expropiación}

a). Notas de este sistema.

Este sistema o procedimiento de ejecución de las obras de urbanización tiene unas notas caracteristicas que se fijan en el artículo 121 de la Ley, y que son las siguientes:

Primera. $\mathrm{Ha}$ de referirse a sectores comprendidos en el Plan general de ordenación urbana, aunque no precisa la previa aprobación de un Plan parcial de urbanización.

Segunda. El Proyecto en que se determinen los terrenos afectados habrá de tramitarse de acuerdo con lo que establece el artículo 32 de la Ley.

Tencera. La expropiación abarcará todos los terrenos comprendidos en el polígono a que se refiere el Proyecto, tanto los 
viales y destinados a zonas verdes, como los edificables, con todos los aprovechamientos, servicios, instalaciones, edificaciones, etc., que allí existan.

b) Quién puede llevarlo a cabo.

El artículo 121 de la Ley dice que los Ayuntamientos y demás Corporaciones públicas y personas privadas a quienes autorice la Comisión Central de Urbanismo, podrán emprender o reservar la urbanización de un sector completo y expropiar uno o varios polígonos sin necesidad de previa aprobación del Plan parcial. El precepto está redactado con poca claridad, y surge la duda si la autorización de la 'Comisión Central se refiere no sólo a los particulares, sino a Ayuntamientos y demás Corporaciones públicas que quieran acogerse a este sistema para urbanizar. $Y$ puesto que después, en el articulo 122, exige para otra materia de menor importancia la intervención de la Comimisión Central, parece que debe interpretarse el precepto en el sentido de someter el asunto a la Comisión Central, en tanto no se aclare oficialmente ia cuestión. Bien es vendad que esto parece estar en contradicción con lo establecido en el punto 4) del artículo 121, pero puede perfectamente someterse al trámite del artículo 32 de la Ley un proyecto de urbanización y ser obligatoria la aprobación del sistema de expropiación por la Comisión Central para ejecutar dicho Proyecto.

Tal vez ha querido el legislador someter en todo caso a una intervención superior la aprobación de un proyecto de este carácter, que lleva consigo la expropiación forzosa con tanta amplitud como la que se acaba de indicar, y tal vez por ello, también, se ha querido que sea la Comisión Central de Urbanismo la que decida las cuestiones suscitadas por los propietarios afectados en el proyecto de expropiación cuando reclamen contra la valoración de sus terrenos o de los derechos sobre los mismos si la tasación se hace de modo conjunto y no individual. 


\section{c) Procedimiento.}

Aprobado, pues, el Proyecto de expropiación dei polígono correspondiente de conformidad con lo establecido en el artículo 32 de la Ley, y aprobada igualmente la ejecución por el sistema de expropiación, el promotor de dicho Proyecto podrá llevar a cabo la expropiación o bien individualmente contra todos y cada uno de los propietarios afectados, o bien mediante un procedimiento de tasación conjunta de la parccla, poligono o sector a que el Proyecto afecta. $Y$ en este último caso se seguirá el procedimiento siguiente:

1. El Proyecto de expropiación se expondrá al público por un plazo que, aunque no se indica, debiera ser, por similitud a lo que se establece en el artículo 32 de la Ley, de un mes, a fin de que los interesados puedan formular las obsenvaciones que estimen pertinentes y presentar las reclamaciones oportunas relacionadas con la valoración que se da a sus derechọs.

2. Terminado el plazo y recibidas las reclamaciones oportunas, el Ayuntamiento, aun cuando no sea él el expropiante (así se deduce del texto de la Ley), informará sobre el particular, elevando después el expediente a ia Comisión Central de Urbanismo.

3. El acuerdo que adopte la Comisión Central de Urbanismo en orden a las tasaciones podrá ser impugnado en reposición, ante la misma Comisión Central, impugnación que habrá de entablarse en el plazo de quince días, debiendo ser resuelto en otro plazo igual, pues en otro caso se considerará desestimado.

d) Limitaciones de los propietarios de los tcrren's afectados en este sistema.

El artículo 122 establece que sobre las fincas afectadas por el Proyecto de expropiación aprobado no se podra realizar construcción alguna ni modificar las existentes sin autorización ex- 
presa del Ayuntamiento, en la forma que se indica en los artículos 46 y 47 , aunque parece que esta cita es errónea y que la referencia es a los artículos 47 y 48 de la Ley.

\section{e) Obligaciones que se imponen al expropiante.}

El que expropia deberá llevar a cabo la urbanización en el tiempo y modo que se hubiera previsto en el proyecto para la aplicación del sistema de expropiación forzosa, así como deberá proceder a la edificación de los solares resultantes. $\mathrm{Y}$ para el caso de que nó se cumpliesen estas obligaciones, se estará a io dispuesto en el artículo 151, en el que se consigna el derecho del antiguo propietario para exigir la reversión de su terreno a fin de edificarlo en el plazo que allí se determina, con los demás particulares que el artículo referido 151 establece.

Claro es que el Proyecto de expropiación pudiera haberje fundamentado en la necesidad de que el Ayuntamiento cuente con reservas de terrenos urbanos para el futuro, y en tal caso podrá incorporar e! polígono o polígonos expropiados al $\mathrm{Pa}$ trimonio municipal, bien que, en todo caso, habría de atenerse a las previsiones establecidas en el Proyecto aprobado por la Su perioridad.

Aunque parece innecesario consignarlo, el legislador establece en el artículo 123 que aquél que hubiera obtenido el derecho a la expropiación, viene obligado a la cesión de los terrenos viales y de los que se destinen a parques y jardines, y a la ejecución, a su costa, de las obras de urbanización; y, si en el Proyecto así se hubiera establecido, vendrá incluso obligado a ceder gratuitamente, o en las condiciones que se hubieran fijado, Jos terrenos que se destinen a edificios públicos o al cumplimiento de fines de notorio interés social.

\section{C) Sistema de Compensación}

\section{a) Idea de este sistema.}

Cuando se hace a él referencia en el preámbulo de la Ley, se dice que es conveniente ofrecer la oportunidad de transformar 
los terrenos en solares a todos los propietarios de un poligono vinculados al resultado de la gestión urbanística mediante un régimen de compensaciones que podrá ser promovido por ellos mismos o por la Administración.

El Ministro de la Gobernación, en el discurso que pronunció al presentar a las Cortes el Proyecto de Ley, decía que por el sistema de Compensación se da realidad al principio de la solidaridad de los beneficios y cargas que deben existir entre los propietarios de un mismo polígono.

No resulta en la Ley muy diferenciado el sistema de Compensación del sistema de Cooperación, aunque existen dos notas por las cuales ciertamente se distinguen uno y otro sistema.

En el de Compensación, todos los terrenos afectados vienen a formar como una masa común, y todos ellos quedan a las resultas de la gestión urbanística, soportando sus cargas y recibiendo los beneficios que se obtengan como consecuencia de dicha gestión, cosa que en realidad no ocurre en el de Cooperación, donde los propietarios se quedan cada uno con sus terrenos y únicamente se obligan a entregar los viales, los destinados a parques y jardines, y a satisfacer el importe de las obras de urbanización dentro de los límites que en los artículos 115 y siguientes se fijan.

Otra de las notas diferenciadoras es que la iniciativa en el sistema de Compensación normalmente estará en manos de los propietarios interesados, en tanto que en el sistema de Cooperación so'amente tienen una intervención, pero no la iniciativa del sistema.

No ha de ocultárse que en la regulación de este sistema, como en realidad ocurre en muchos artículos de la Ley del Suelo, se hacen necesarias normas reglamentarias que los complementen y puntualicen, eliminando muchos motivos de duda y vacilación que hoy se ofrecen al dar aplicación a sus preceptos.

El artículo 124 de la Ley dice que el sistema de Compensación es aquel en el que los propietarios de terrenos comprendidos en unos o varios polígonos, se unen con fines de urbaniza- 
ción y, en su caso, ae edificación, con solidaridad de beneficios y cargas bajo una gestión común, a ouyo efecto constituirán una Junta de Compensación con propia personalidad y piena capacidad jurídica.

Según, pues, la concepción que del sistema tiene el legislador es que los terrenos a que afecte un polígono cuya urbanización ha de llevarse a cabo, según proyecto debidamente aprobado, forman una unidad y se someten a las consecuencias de la urbanización, soportando los gastos y haciendo suyos los beneficios de la misma en proporción al valor de la aportación hecha por cada propietario. Y para llevar a cabo esa gestion común de carácter urbanizador se crea una persona jurídica que es la Junta de Compensación, que tendrá plena capaciảad jurídica para realizar cuantas funciones y actividades sean precisas en orden al cumplimiento de los fines para los que se crea.

Como es de razón, serán los mismos propietarios los que habrán de fijar las bases conforme a las cuotas en que se ha de desenvolver la gestión común, precisando cómo han de vaiorarse los terrenos que se aportan a la masa común, cómo han de repartirse después los solares resultantes, y cómo ha de hacerse frente a las cargas y obligaciones nacidas de esa gestión común encaminada a la realización de la urbanización y al reparto posterior de los solares resultantes.

A esta gestión común, dice el párrafo tercero del artícuJo 124, podrán incorporarse los Ayuntamientos y órganos urbanísticos, e igualmente las empresas urbanizadoras que aporten total o parcialmente los fondos necesarios para urbanizar en las condiciones que se determinen. Lo que no se puntualiza es si en ese podrán va implícita una obligación para los propietarios o, por el contrario, éstos podrán desligarse totalmente de la intervención, a efectos de aguantar las cargas o de repartirse los beneficios con el Ayuntamiento respectivo y los órganos urbanísticos, aunque parece de razón que si la iniciativa ha partido de los propietarios mismos y éstos quieren llevar a cabo ellos so:os la gestión urbanizadora, puedan no admitir a esa gestión común al Ayuntamiento ni a los órganos urbanisticos, aun- 
que siempre la fiscalización y el control estarán en manos de la Administración.

b) Proyectos urbanísticos para realizar por Compensación.

Nada se dice sobre si el Proyecto que haya de aprobarse para llevar a cabo, mediante este sistema de Compensación, la gestión urbanizadora, ha de hallarse comprendido en un Plan general, y si no es preciso el Plan parcial correspondiente, como respecto del sistema de Expropiación se determina en ei artículo 121 de la Ley. Desde luego, que una actividad urbanística como de la que se trata habrá de hallarse comprendida dentro del Plan general de ordenación urbana; sin embargo, no parece que sea preciso el Plan parcial, sino que bastará entonces con que se apruebe el Proyecto que ha de realizarse por el sistema de Compensación. $Y$ en tal Proyecto se habrán de señalar el polígono o polígonos afectados, y será menester dar cumplimiento a cuanto se establece respecto de la formación y aprobación de los Planes de ordenación urbana. Se precisarán además alineaciones, rasantes, características de vías y plazas, espacios libres, emplazamientos reservados a servicios públicos, uso reglamentario de los terrenos, con indicación de alturas, destinos, etc., y el Proyecto habrá de someterse a la tramitación establecida en el artículo 32 de la Ley.

\section{c) Iniciativa en el sistema de Compensación.}

La iniciativa para la aplicación de este sistema puede ser de los propietarios, de los Ayuntamientos o de otros órganos urbanísticos.

a') Cuando la iniciativa parta de los propietarios, dice la Ley en el artículo 125 que para poder ser tomada en consideración ha de estar representado al menos el cincuenta por ciento del valor de la propiedad del polígono o polígonos a que se refiere e! Proyecto de Compensación. 
Como puede apreciarse, ha introducido aquí el legislador el concepto de "valor", que no dejará de originar dificultades de apreciación. Tal vez hubiera sido mejor decir sencillamente el 50 por 100 de la propiedad afectada sin mayores determinaciones relativas al valor, que puede ser difícil de determinar o que puede dar lugar a discrepancias y cuestiones litigiosas.

Exige luego ei artículo 125, el que tales propietarios han de obtener del Ayuntamiento la delimitación del polígono y la aprobación del sistema, para lo cual habrán de presentar los documentos necesarios para determinarlo.

Al aprobar el Ayuntamiento la delimitación del polígono, habrá de fijar el plazo dentro del cual los propietarios de los terrenos afectados por el Proyecto e incluídos, por tanto, en el polígono correspondiente, pero que aún no forman parte de la Asociación de propietarios, puedan solicitar su incorporación a la misma.

Este plazo tiene gran importancia, pues, transcurrido el mismo, la Junta de Compensación podrá proceder a la expropiación forzosa de los terrenos que no se hubieran incorporado a aquélla. Para poder adoptar esta decisión la Junta de Compensación, han de formar parte de ella terrenos que al menos cubran el 60 por 100 del polígono o polígonos afectados, según establece el párrafo segundo del artículo 125.

No parece que exista razón para establecer una diferencia en la fijación de la participación: para tomar la iniciativa del sistema se exige el cincuenta por ciento del valor de la propiedad afectada, ahora el 60 por 100 de la total propiedad del polígono, introduciéndose, como puede apreciarse, no sólo dos participaciones distintas, el 50 por 100 y el 60 por $\mathbf{1 0 0}$, sino diferencia en el cómputo, pues para la iniciativa se exige el 50 por 100 del valor, en tanto que para considerarse constituída la Junta de Compensación se requiere el 60 por 100 de la total propiedad afectada, sin referencia alguna al valor.

Se permite también por la Ley que los propietarios puedan pedir al Ayuntamiento o a los órganos urbanísticos la constitución de una Sociedad mixta. Es decir, que si los propietarios 
no quieren solicitar la constitución de esta Sociedad, no se ies podrá imponer, ni tampoco ellos podrán imponer a: Ayuntamiento y órganos urbanísticos la entrada en dicha Sociedad.

b') En el caso de que la iniciativa de la aplicación del Pro. yecto de Compensación se deba al Ayuntamiento o a otros órganos urbanísticos, se podrá hacer lo siguiente:

1. Invitar a los propietarios a que constituyan la Junta de Compensación en la forma que se determina en los párrafos segundo y tercero del artículo 125, es decir, que formen dicha Junta los propietarios de los terrenos afectados que integren al menos el 60 por 100 del total de la propiedad del polígono o polígonos afectados. $Y$ si en el plazo que al efecto se determine por el propio Ayuntamiento hubiera propietarios que no se hubieran adherido a la Asociación, podrá la Junta de Compensación proceder a la expropiación forzosa de los terrenos no incorporados, prosiguiéndose, en tal caso, a llevar todo el procedimiento en orden a la constitución de dicha Junta con plena capacidad jurídica, fijación de las bases con arreglo a ias cuales se determina la aportación de los terrenos y reparto de cargas y beneficios que puedan producirse como consecuencia de la gestión común urbanizadora.

2. Invitar igualmente a los propietarios a que constituyan la Junta de Compensación en el modo como se determina en el párrafo segundo del artículo 125 (de donde parece deducirse que es preciso que para que puedan constituir dicha Junta se reúna el 60 por 100 de la propiedad total del polígono), pero corriendo a cargo del Ayuntamiento la expropiación de los terrenos que no se hubieran integrado en la Junta de Compensación.

3. Constituir, juntamente con lios propietarios afectados, una Asociación mixta sobre las bases que proponga el Ayuntamiento, y que, de no ser aceptadas por los propietarios, permitirá que la Corporación municipal pueda proceder a la expropiación forzosa de los terrenos de aquellos propietarios que no se hubieran mostrado conformes con el Proyecto y las Bases, pudiendo también la Corporación desistir del sistema de Compensación para la ejecución del Proyecto de urbanización. 
d) Incumplimiento de las obligaciones contraidas por los propietarios.

Autoriza el artículo 128 a la Junta de Compensación para poder expropiar los terrenos de aquellos propietarios que no cumplan con las obligaciones contraidas, estableciendo al efecto que la indemnización por la expropiación de dichos terrenos será sólo del 75 por 100 del valor inicial, indemnizando además el importe de las obras de urbanización que hubieran sido abonadas por el interesado. Este valor inicial se determinará de acuerdo con las normas que al efecto establece la Ley en sus artículos 85 y siguientes.

Puede ocurrir que deje incumplida sus obligaciones la misma Junta, y entonces el Ayuntamiento podrá exigir que se le dé iepresentación en dicha Junta, o bien podrá llegar a la expropiación total o parcial de los terrenos a que afecte el Proyecto de Compensación.

Es lógico, y así lo consigna el artículo 128, que los propietarios que hayan cumplido sus compromisos continúen en idéntica situación a que tenían derecho según los Estatutos aprobados para la aplicación del sistema de Compensación, cuando tenga que llevarse la ejecución por el Ayuntamiento o por el órgano urbanístico correspondiente en los casos antes indicados.

e) Otras facultades de la Junta de Compensación.

La Junta de Compensación, que como ya se ha dicho tendrá una personaiidad propix y capacidad jurídica plena en onden al cumplimiento de los fines para los que se constituyó, podrá concertar créditos a fin de llevar a cabo las obras de urbanización del Proyecto aprobado. Estos créditos tendrán como garantía los terrenos incluidos en el polígono o polígonos a que los Proyectos afecten. 
En el caso de obtener beneficios en la gestión urbanística que se lleve a cabo, después de haber satisfecho los gastos de gestión del Proyecto y de urbanización, se distribuirán entre ios propietarios en la medida que hubieren contribuído a los gastos. $\mathrm{Y}$ en el caso de haberse emitido títulos, tales beneficios se distribuirán entre los poseedores de dichos títulos y los propietarios en la proporción que se establezca al efecto.

Razonablemente ha de pensarse que al constituirse la Junta de Compensación y fijarse las bases de derecho para los propietarios que formen parte de la Asociación, habrá de determinarse, como lo establece el antículo 124, el modo de distribuir las cargas y los beneficios que puedan producirse en la gestión urbanística que la Junta de Compensación haya de llevar a cabo.

\section{D) Sistema de Cesión de terrenos viales}

En términos generales, el Ayuntamiento, o el órgano gestor en su caso, podrá elegir el sistema aplicable a la realización o ejecución del Plan y Proyecto de urbanización, aunque, como antes se ha indicado, cuando se trate del sistema de Compensación, podrá partir la iniciativa de los mismos propietarios afectados por la urbanización proyectada.

En el artículo 113 de la Ley se indica también que en el caso de no determinarse el sistema que hubiera de seguirse en un polígono determinado, o que cuando no se acordase por el órgano gestor de la urbanización qué sistema habrá de aplicar en orden a la ejecución del Plan, tiene carácter preferente el sistema de Cooperación si se trata de sectores o vias de nueva urbanización, y el de Cesión de terrenos viales con la imposición de Contribuciones Especiales cuando se tratare de sectores par cia'mente urbanizarlos y edificados.

Lo expuesto parece permitir a los Ayuntamientos que cuando no se hubiera ya establecido con anterioridad en el Plan de urbanización un sistema de ejecución (cosa que ocurrirá la mayor parte de las veces), podrán acordar el sistema que estimen oportuno, si bien la declaración de preferencia estabiecida a fa- 
vor del de Cooperación, cuando se trate de nueva urbanización, y la de Cesión de terrenos viales con la imposición de Contribuciones Especiales, cuando se trate de sectores parcialmente urbanizados, parece indicar que habría de atenerse la Corporación a la aplicación de estos dos sistemas en tales casos. Pero esta materia requiere ser matizada con normas reglamentarias, como tantas otras cuestiones de la Ley del Suelo.

En el artículo 129 se refiere el legislador al sistema de Cesión de terrenos viales, diciendo que es aquél en el que los propietarios vienen obligados a ceder al Ayuntamiento correspondiente los terrenos viales y los destinados a parques y jardines, según las normas y limitaciones establecidas en el artículo 116 al tratar del sistema de Cooperación.

El costo de las obras de urbanización en este sistema no irá, como en el de Cooperación, a cargo en su totalidad, o con las limitaciones establecidas en el artículo 117, de los propietarios, sino que se distribuirá entre el Ayuntamiento y los propietarios afectados, aplicando las Contribuciones Especiales, contribuciones que no podrán dejar de imponerse ni percibirse en ningún caso, según dice el artículo 130 , y cuyas cuotas cabrá exigir con seis meses de anticipación en proporción a los gastos que se prevean para dicho período.

Este precepto suscita algunas dificultades respecto de su aplicación. En primer lugar, parece que al exigir que, en todo caso, se impongan las Contribuciones Especiales, se va más allá de lo que exige la Ley de Régimen local, la cual, en su artículo 451, solamente establece con carácter de obligatoriedad la' imposición y exacción de las Contribuciones Especiales cuando haya aumentos determinados de valor. Por lo demás, ha de estimarse que toda la regulación de la Ley de Régimen local vigente en orden a las Contribuciones será de aplicación en ei sistema de Cesión de terrenos viales.

Si los procedimientos a que antes se ha hecho referencia se ponen en práctica, y ésta es cuestión que mucho importa a los 
Ayuntamientos, se podrán llevar a cabo urbanizaciones que esperan hace años su hora, siempre demorada por razones económicas. Es verdad que siempre los primeros pasos originan dudas y dificultades, pero es necesario comenzar a desbrozar el camino. La experiencia irá poniendo de relieve defectos que corregir y lagunas que rellenar; si no se comienza la tarea, y se hace la letra de la Ley causa de necesidad, nos condenamos a una inacción que carece de justificación.

Junto a los mencionados sistemas de la Ley del Sucio, que favorecen iniciativas, aunque imponen obligaciones de mayor monta a los propietarios afectados, ofrece también la Ley estímulos económicos de gran importancia. Los propietarios pueden obtener cesiones de impuestos del Estado y del Municipio, así como exenciones tributarias de importancia, y los Ayuntamientos pueden también hacer uso de una gama de ingresos que reforzarán notablemente los medios económicos y financieros destinados a la acción urbanística.

Los artículos 175 y siguientes de la Ley del Suelo puntualizan toda esta importantísima materia, tanto para las Corporaciones municipales como para los propietarios afectados por los proyectos de ordenación urbana a poner en práctica.

Si junto a la puesta en marcha del mecanismo jurídico-legal se dicta el Reglamento que facilite la aplicación de la Ley, pueden cosecharse óptimos frutos en el campo de la ordenación urbanística. 